\title{
Combating animal rights extremism
}

David Jentsch, an associate professor at the University of California, Los Angeles (UCLA), awoke one night in March to find that his car had been firebombed. An underground animal rights group called the Animal Liberation Brigade later claimed responsibility for the attack. To some degree, Jentsch, who studies neurological disorders in monkeys, had anticipated the assault; many of his colleagues at UCLA had already been threatened and their property vandalized by animal rights extremists. In 2006, such harassment led one UCLA neurobiologist to give up animal research altogether. $\mathrm{He}$ announced his decision in an email to animal rights groups, in which he stated simply, "You win."

Today, researchers are less willing to give violent extremists the upper hand. Encouraged by shows of support from colleagues and students, Jentsch decided to take action on behalf of biomedical research. With the help of Tom Holder, a founder of the research advocacy groups

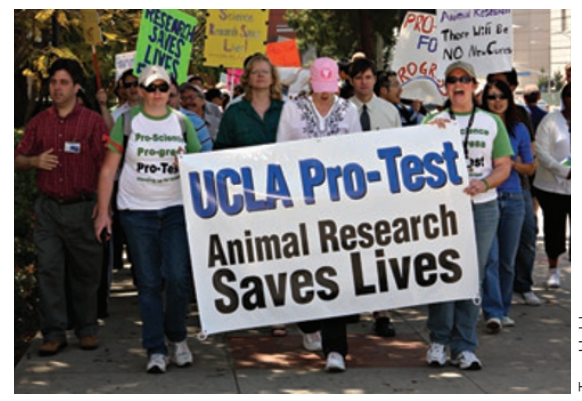

Pro-Test and Speaking of Research (based in the UK and in the US, respectively), Jentsch formed a group called UCLA Pro-Test.

On April 22, the same day that an animal rights demonstration was being held on the university campus, UCLA Pro-Test held a rally in support of research. The rally drew more than 700 people and received extensive coverage in major media outlets, including the Los Angeles Times, $\mathrm{CNN}$ and National Public Radio.

There have been other indications in recent weeks of increasing public opposition to animal rights extremism.
The day before the Pro-Test demonstration, the Counterterrorism Division of the FBI announced that an American animal rights activist, Daniel Andreas San Diego, would be added to the Most Wanted Terrorist List. This is the first time a domestic terrorist has been included in the list. San Diego was allegedly involved in the bombing of two animal research facilities. His actions were part of an ongoing campaign to put Huntingdon Life Sciences-a contract research institution that carries out experiments in animals—out of business.

Activists such as Jentsch and Holder, as well as pro-research organizations such as the Foundation for Biomedical Research and Americans for Medical Progress, continue to speak out in support of scientists and encourage scientists to stand up for themselves. "That horrible face that comes in the night can't come anymore-it has to stop," Jentsch told the crowd of supporters. "We have to persist. We have to be strong. We will win."

\section{Karen Marron}

\section{PARROTS GET IN THE GROOVE}

Despite an extensive collection of videos online claiming to show animals dancing, the ability to perceive and synchronize with a musical beat has largely been considered a uniquely human trait. That is, until now: two groups of researchers recently showed that parrots can boogie down with the best of us.

Aniruddh Patel (The Neurosciences Institute, San Diego, CA) worked with colleagues at University of California (San Diego) and the owners of a sulphur-crested cockatoo named Snowball to document Snowball's dancing ability, after Patel saw an online video of Snowball getting down to the Backstreet Boys' song "Everybody". When Patel manipulated the tempo of the tune and played the faster versions to Snowball, the bird adjusted the tempo of his movements to remain synchronized with the beat (Curr. Biol. published online 30 April 2009; doi:10.1016/j.cub.2009.03.038).

In a companion study, Adena Schachner (Harvard University, Cambridge, MA) and colleagues at Massachusetts Institute of Technology (Cambridge) and Brandeis University (Waltham, MA) confirmed that Snowball and an African grey parrot named Alex (who was wellknown as a research subject prior to his unexpected death in 2007) both spontaneously moved in sync with music (Curr. Biol. published online 30 April 2009; doi:10.1016/j.cub.2009.03.061). Schachner's group also analyzed a large selection of videos of purportedly dancing animals posted online and found that 14 different species of parrot were able to coordinate their movements with a beat.

The findings of both groups lend support to the hypothesis previously put forth by Patel that the ability to synchronize movement with music is linked to the capacity for vocal mimicry (learning and imitating sounds). Vocal mimicry is limited to humans, certain birds, cetaceans, pinnipeds, elephants and some bats but has not been demonstrated in other animals closely associated with humans, such as nonhuman primates or common domesticated species like cats and dogs. All of the animals that moved to the beat according to Schachner's study are vocal mimics, in keeping with Patel's hypothesis that only such animals should show rhythmic coordination. Furthermore, avian species are not known to coordinate their movements with auditory rhythms in their natural environments, meaning that the behavior must not be under direct natural selection and instead must have developed as a byproduct of some other ability.

Patel's and Schachner's results suggest that animal movement models may provide insights into the neurobiology and evolution of human response to music. Monica Harrington 